by the head, or is it materially assisted by some other structure in relation to the perineum? It appears to me that there is a powerful agent besides the head, which has literally been pressed into the service, the action of which, in formulating any plan for the management of the perineum, ought to be carefully kept in view. This agent I believe to be the levator ani muscle. This muscle arises on each side from the back of the symphysis pubis and whibe line, and, running downwards and backwards by the side of the bladder and Tagina, is inserted into the perineum from the central point backwards to the coccyx. The effect which these muscles would exert upon the perineum is evident. With the head pressing backwards upon the rectum, both muscles, and particularly their anterior portions, inserted in front of the rectum, would be put upon the stretch, and by their traction would tend to pull the front of the periaeum forwards. In facb the perineum may not inaptly be compared to a hammock, having its attachments behind to the sacrum and hips, while the ropes slinging it above and in front to the pubes are the levatores ani mnscles. It will further be noted that a peculiarity of the perineal hammock is that the anterior ropes are not tied to its front only, but are fixed along the whole bed up to the central point, while all between the latter and the vagina is free. The effect of these peculiar attachments is plain. The front of the perineum, immediately adjacent to the vulva, is left free and untrammelled-an obvious advantage, as it is the part which will have to be stretched to allow the head to come through. On the other hand, the portion behind, while much strengthened on its sides by muscle, is weakened along the middle line of its floor, this being the line along which the levatores ani are attached, and which is subjected to the greatest amount of traction. It is along this line that the perineum splits. Granting this view to be a correct one, the principles which should be kept in view are-1. Interfere with the natural tendency of the parineum to be pulled forwards as little as possible. 2. Leave the front of the perineum quite unfettered, to dilate as freely as its structure will admit. 3. Take off the tension from the middle line, along the insertion of the levatores ani muscles. All these requirements are completely flulfilled, together with that fourth and very important one, maintenance of flexion of the fotal head, by pressure applied just in front of the coccyx in an upward and forward direction. By so doing the perineum is helped forward, the tension of the levatores ani upon the floor of the verineum is relieved, the head is kept flexed and closely applied to the pubes, while the anterior part of the perineum is left free to dilate. The plan I have found most convenient is to apply pressure with the thumb of the right band, the fingers boing free to control the passage of the head through the vulva, should it be deemed desirable to delay the birth till more complete dilatation has taken place. The results which I have obtained by a practical application of these principles to fifty cases of vertex labour at full term are: Torty-three multiparas, two tears ; seven primiparas, one tear. Of the three tears, none of them were serious. One was laterul, through the hinder part of the left labium, and one oceurred during the birth of the abdomen. The tear in the primipara was half an inch long and only skin deep, the septum remaining intact. It needed only a single catgut stitch to bring it together.

To sum up, the conclusions which I would venture to put forward are :-1. That rotation is not the result of the inclined planes of the pubes and ischial spines, but of the narrowing of the transverse diameter towards the outlet due to the inward, downward, and backward slope of the pelvic floor. 2. That the head in occipito-anterior presentations is born, not by extension, but in a state of flexion. 3. That the perineum is best preserved by a method which maintains flexion of the head, relieves the tension along its floor, and interferes as little as possible with its normal action in labour.

Adelaide-road, N.W.

The Fulhanr Mortuary.-A member of the Fulham Vestry, at a recent meeting of the Sanitary Committee, described from his own personal observation a revolting state of things at the Fulham Mortuary, which drew forth strong animadversion from the meeting. Cltimately a subcommittee was appointed to visit the mortuary, accompanied by the medical officer, and report the steps necessary to be taken for its better equipment and management.

\section{NOTE OF A CASE OF TUMOUR OF THE BRAIN THE RESULT OF AN APOPLEXY.}

\author{
By J. A. CAMPBELL, M.D.
}

With Reyort of the STruCture of the TuMour BY JOSEPH COATS, M.D.

W. $M-$, aged thirty-three, was admitted into the Carlisle Asylum on Nov. 17th, 1870. He had not been considered well in mind for six years; when a child he had had fits. Though none of his near relatives had been in an asylum, some of them had been very peculiar. Previous to his admission he had been dull and morose, wishing himself dead, and threatening to injure his father.

On admission he was found to have a good memory, to speak coherently, to reply to questions correctly; but he was in a state of very considerable depression, as shown by his appearance, attitude, manner, conduct, and remarks. A careful note was made of his bodily condition, but I need merely quote that he was a dark-complexioned man of $5 \mathrm{ft}$. $11 \mathrm{in}$. in height, and $167 \mathrm{lb}$. in weight. His temperature and pulse were both slightly above normal, but no disease was detected in his various organs. For some time he was returned as being dull and taciturn, seldom conversing with others and always very peculiar in his conduct and habits, never wishing to leave the place, and on the whole industrious and in good health. For nine years he continued in this state, but in October, 1879 , he complained of rheumatic pains for a short time. Only once or twice during this period did he show real signs of being dangerous to others, on one occasion attacking a fellow-patient with a spade. Both attendants and fellowpatients thoroughly recognised that he was not a man to be trifled with, so that for the most part he got his owu way, and therefore behaved quietly. In October, 1886, after sixteen years' residence, physical examination showed no indications of disease, except that the respiratory murmur over the right apex was harsher than over the left. His heart was carefully examined, and nothing abnormal was detected about it. In January, 1891, he did not look quite so well as nsual, and was therefore allowed one pint of porter daily, but at this time he was $17 \mathrm{lb}$. heavier than when he came in. On July $3 \mathrm{rd}$ he had a paralytic seizure, with slight loss of power on his right side. He complained of a feeling of giddiness, but there was no change in his mental condition, and he spoke as usual. On July 12th he had a fit, after which the paralysis increased. His right arm remained powerless but his leg shortly regained power. During August the patient improved, regained a certain amount of power in his right arm, and more in his leg. In the first half of September he deteriorated, his arm and leg dwindling considerably, and he was reported to have had several slight fits at night. On Sept. 15th a pustular eruption like a half oval in shape appeared over the lower part of the abdomen. He became suddenly comatose on Sept. 30th, and continued so till his death on Oct. 3rd, 1891-three months exactly after the date of his first attack. I thought his first seizure due to an apoplexy in the left hemisphere, in the region of the centres controlling the arm and leg. I considered that the slight fits which were from time to time reported as affecting him at night (though I never was fortunate enough to see him in one) were caused merely by the cerebral irritation consequent on altering blood-clot; and I thought the final attack with complete coma was due to a further and more extensive hæmorrhage, probably in the same locality as the first. In considering the patient's case the question of brain tumour was discussed; but I decidedly favoured the diagnosis of apoplexy from the suddenness of the initial seizure, the partial recoveries of power which took place in the implicated members, the absence of the train of mental phenomena usually witnessed with growing tumours, and the character of the final and fatal seizure.

A post-mortem examination was made forty-one hours after death. The body was rather emaciated. The organs 
were carefully examined, their condition noted, and their weights recorded; and, with the exception of the brain, they were go far normal as not to call for comment. I shall therefore merely quote from my register the account of the appearances of the contents of the skull. Head: scalp thin, calvaria thickened; dura mater was not adherent to the bone, nor was it thickened. The state of the other membranes does not call for notice. On separating the hemispheres there was found to be a tumour the size of an orange in the right hemisphere; it was placed immediately above the lateral ventricle of that side. In consistence it was tirm; it appeared encapsuled, and required no dissection to remove it from the brain. The tumour included the gyrus fornicatus and corpus callosum, or had displaced these and caused their atrophy; it lay rather more posteriorly than anteriorly. Io did not cause any change in the appearance of the surface of the brain, and its presence could not be detected till the hemispheres were separated. The tumour weighed five ounces. Section of the brain showed no naked-eye changes other than atrophy of the grey matter. The arteries at the base were atheromatous. I examined a minute portion of this tumour, and found large, round, and spindle cells; but I was so much astonished at finding such a large tumour with such a short known period of illness, with such an onset and train of symptoms, that I asked my friend, Dr. Coats of Glasgow, to examine the tumour and give me a report upon it. I told him I had diagnosed sanguineous apoplexy, and that I was exceedingly surprised at the post mortem revelations. The fol lowing is the report with which Dr. Coats kindly furnished me:-

"The specimen sent is a pyriform mass, measuring, after preservation in alcohol, $2 \frac{3}{4}$ in. $\times 2 \frac{3}{8}$ in. $\times 1 \frac{3}{4}$ in. It is very firm to the touch and generally smooth on the surface. A section having been made through the mass from apex to base, the cut surface is seen to present a somewhat varied appearance. The greater part shows a brown colour, and this presents frequently an appearance of partial disintegration, but without any absolute formation of cavity or cyst. Besides this brown substance there is a whitish structure which looks like fibrous tissue; this is especially seen at the surface, where there is an approach to a capsule formed by this fibrous-looking tissue; but it also extends at one place for some distance into the substance of the mass. Microscopic examination shows the layer on the surface to be composed essentially of spindle-shaped cells. This layer is not absolutely continuous, but covers most of the surface, and it is thin, attaining generally to about the thickness of the twenty-fifth of an inch, although sometimes extending considerably more. In connexion with this layer, but even more in the parts immediately beneath, there are frequently groups of large vessels, thin-walled and distended with blood. Beneath the spindle-celled layer the mass of the tumour is composed of a rather indefinite structure. There are many round cells, which to a considerable extent lie in masses separated by fibrous matter. This fibrous matter has, when the section is treated by ordinary methods, a vague structureless appearance. It runs among the cells forming a kind of basis, and often assuming greater proportions, so as to form strands dividing the masses. It has not, however, the aspect of wavy connective tissue, and on staining it shows no nuclei apart from those of the contained round celle. The appearance of this fibrous matter, suggested fibrine, and this view is completely confirmed by staining with Weigert's fibrine stain. This brings out frequently the finely fibrillated appearance of fibrine and shows that it exterds intimately amongst the cells."

Dr. Coats is of opinion that this has been a large bloodclot, which was undergoing the process of organisation. The stages of this process are similar to those in the organisation of a thrombus, as described and illustrated in Coats' Manual of Pathology, second edition, p. 70 . After the blood has coagulated there is first a penetration and replacement of it by round cells and bloodvessels, this being the stage represented in the greater part of the present specimen. After this the round cells elongate and spindle cells are produced. The process extends from without inwards, and here the surface has alone got the length of spindle-cell tissue. It is very unusual for a coagalum to undergo this process in the brain, but it is also very unusual for a patient to survive after such a large hæmorrhage as this must have been.

Carlisle.

\section{Clinital : glotes:}

MEDICAL, SURGICAL, OBSTETRICAL, AND THERAPEUTICAL.

\section{CONVULSION TREATED BY COMPRESSION OF} THE CAROTID.

By Whlter C. Hearnden, M.R.C.S.

IN the issue of THE LANCET of Jan. 2nd there was an annotation giving an account of Dr. Leopold Roheim's treatment of eclampsia by compression of the carotid. The following case occurred in my practice the other day, and? from the rapid success of the treatment I think it worthy of record:-

A. H-, widow, aged sixty.one, had been under my care as a pauper patient on and off for some years suffering from chronic rheumatic gout. She was seized with in. fluenza and had a severe attack of bronchitis, which made her very weak, and I had great difficulty in obtaining any nursing or assistance in feeding her. However, she was doing fairly well; when on seeing her on the 15th I found she had paralysis of the right side of the face, arm, and leg. I saw her on the following morning, and in the evening a, half-past ten I was sent for to see her, as she was said to be dying. When I arrived I found her in a fit, which the attendant said had been going on for two hours. Her eyes were turned to the right, face and body twitching, and she was puffing away like a steam engine. I looked on it as a case of embolic plugging in the left hemisphere and hyperæmia of the right, as the eyes were turned to the right side; and, having Dr. Roheim's treatment fresh in my mind, I thought I would compress the right carotid. I found it rather difficult, the patient being very fat, the throat moving up and down in the convulsion, and the carotid beating with such force that it was difficult to prevent it running under the thumb. I used the thumb to compress, the rest of the hand getting power from behind the neck. In a few seconds only the twitchings began to cease, then the breathing grew slower and deeper, and in not more than a minute and a half or two minutes the face grew calm, the eyes regained their position, and there was an attempt on the patient's part to wipe the lips with the sound hand. I then left off the compression, For a minute or two the patient went on breathing calmly, then suddenly the eyes went up to the right the face twitched, the breathing became again puffing, and the body was convulsed. I immediately compressed the carotid again as firmly as possible, and had the great satisfaction of seeing the patient in certainly less than two minutes come out of the fit, give me her hand, and pull herself up in bed, and, although dazed, still sufficiently clear to attempt to put out her tongue when told to do so. I left her to the nurse and she had no return of the fit. I knom of no other treatment that could have been adopted in an emergency that would have so rapidly relieved the patient. Leatherhead, Surrey.

\section{"OCCLUDED OS AT FULL TIME."}

By Robert S. Cochrane, M.B. Dub., F.R.C.S.I.

UNDER this heading two cases are reported by Dr. Nast in Trie LanceT of Jan. 30th. About a year ago I met one very similar, which may perhaps be worth publishing.

On the evening of Feb. 25th, 1891, I was called in with my friend, Dr. Atkinson, to the following case. A primi. para, thirty years of age, in labour over twelve hours Pains very frequent and severe. On examining, we found the head low down in the pelvis, completely covered by the uterus. Neither of us could detect any trace of an os; no thickening or roughness, or the least depression appreciable by the finger. The pains increasing and becoming more violent, we drew the patient over to the side of the bed, and introduced a large-sized Ferguson's speculum. Throngh it, and with the aid of a strong light, we were able to see $\mathrm{s}$ very slight indentation where we would expect to find the os. Keeping the speculum in position, we pressed a sound 